\title{
RELATION BETWEEN KINESIOPHOBIA, FUNCTIONAL MOBILITY AND PAIN FOR PATIENTS AFTER LUMBAR HERNIATED DISC SURGERY
}

\author{
Gintare Čepanonyte் ${ }^{1}$, Alma Cirtautas ${ }^{1,2}$ \\ ${ }^{1}$ Vilnius University Faculty of Medicine Department of Rehabilitation, Physical and Sports Medicine \\ ${ }^{2}$ Vilnius University Hospital Santaros Klinikos Rehabilitation, Physical and Sports Medicine Centre \\ Vilnius, Lithuania
}

Introduction: Herniated disc is most common in people over 30 and twice more likely to occur in men than women [1]. Consequently, surgical interventions for the treatment of these conditions are constantly increasing [2]. Kinesiophobia is considered to be of great importance for physical recovery after disc hernia surgery [3].

Purpose: To identify relation between kinesiophobia, functional mobility and pain for patients after herniated disc surgery.

Method: Patients after lumbar herniated disc surgery have participated in the study. Patients functional mobility, isometric muscle strength of lower limbs, level of kinesiophobia, level of pain were assessed at the early stage after herniated disc surgery. All patients enrolled in the trial were tested one time.

Results: Functional mobility after lumbar herniated disc surgery is dependent on level of kinesiophobia $(\mathrm{p}<0,05)$. Patients with higher level of kinesiophobia had lower functional mobility. The medium correlation found between functional mobility, the strength of the affected leg and intensity of pain $(p<0,05)$ (Table 1.). Patients with higher pain intensity had lower functional mobility as well as weaker muscle strength of affected leg. Medium correlations $(p<0,05)$ found between age and functional mobility as well as between age and the subscales ,,activity avoidance“ and „somatic focus“ of kinesiophobia (Figure 1.). Older patients had lower functional mobility, were more likely to fear the activities of movement and to have higher somatic level.

Discussion and Conclusions: The medium correlation found between functional mobility and muscles strength of affected leg, level of kinesiophobia, intensity of pain and age. The muscle strength of affected leg was influenced by gender.

\section{Sources:}

1. Informed Health Online. Slipped disk: Overview. Institute for Quality and Efficiency in Health Care (IQWiG). 2016.

2. McGregor AH, Dore CJ, Morris TP, Morris S and Jamrozik K. Function after spinal treatment, exercise and rehabilitation (FASTER): improving the functional outcome of spinal surgery. BMC Musculosceletal Disorders. 2010 January; 11:17.

3. Domenech J, Sanchis- Alfonso V, Lopez L and Espejo B. Influence of Kinesiophobia and Catastrophizing on Pain and Disability in Anterior Knee Pain Patients. Knee Surg Sports Traumatol Arthrosc. 2013 July; 21(7):1562-1568.
Table 1. Relation between functional mobility, muscles strength of the affected leg, intensity of pain and age

\begin{tabular}{|c|c|c|c|l|c|}
\hline & Keitel & VAS & $\begin{array}{l}\text { Bending } \\
\text { muscles } \\
\text { strength }\end{array}$ & $\begin{array}{l}\text { Straightening } \\
\text { muscles } \\
\text { strength }\end{array}$ & Age \\
\hline Keitel & 1 & $\begin{array}{c}\mathbf{p}<\mathbf{0 , 0 5} \\
\mathbf{r}=\mathbf{- 0 , 5 1}\end{array}$ & $\begin{array}{r}\mathbf{p}<\mathbf{0 , 0 5} \\
\mathbf{r}=\mathbf{0 , 5 8}\end{array}$ & $\begin{array}{c}\mathbf{p}<\mathbf{0 , 0 5} \\
\mathbf{r}=\mathbf{0 , 5 7}\end{array}$ & $\begin{array}{c}\mathbf{p}<\mathbf{0 , 0 5} \\
\mathbf{r}=\mathbf{- 0 . 4 5}\end{array}$ \\
\hline VAS & 1 & $\mathbf{p}<\mathbf{0 , 0 5}$ & $\mathbf{p}<\mathbf{0 , 0 5}$ & $\mathrm{p}>0,05$ \\
$\mathbf{r}=\mathbf{- 0 , 6 0}$ & $\mathbf{r}=\mathbf{- 0 , 6 4}$ & $\mathrm{r}=0.29$ \\
\hline $\begin{array}{c}\text { Bending } \\
\text { muscles } \\
\text { strength }\end{array}$ & & & 1 & $\mathbf{p}<\mathbf{0 , 0 5}$ & $\mathrm{p}>0,05$ \\
\hline $\begin{array}{c}\text { Straightening } \\
\text { muscles } \\
\text { strength }\end{array}$ & & & & $\mathbf{0 , 9 6}$ & $\mathrm{r}=-0.18$ \\
\hline
\end{tabular}
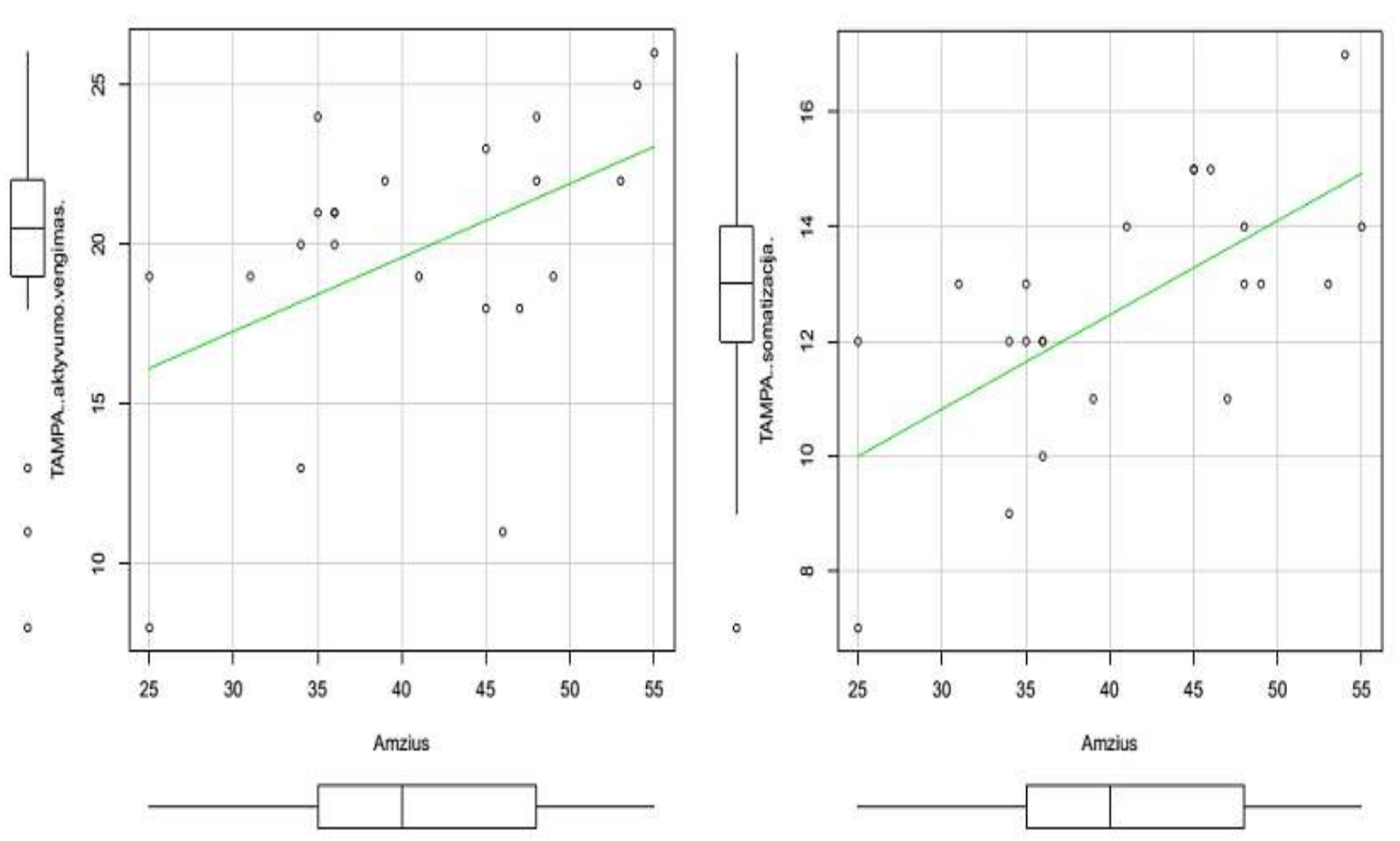

Figure 1. Correlation between age and TAMPA subscales for ,activity avoidance" and ,somatic focus. 